С. М. Николаев, С. А. Чукаев, О. А. Роднаева, В. Е. Хитрихеев. Желчегонное действие экстракта сухого Carthamus Tinctorius $L$.

Научная статья

УДК $615.324: 017$

DOI: $10.18101 / 2306-1995-2021-1-3-8$

\title{
ЖЕЛЧЕГОННОЕ ДЕЙСТВИЕ ЭКСТРАКТА СУХОГО CARTHAMUS TINCTORIUS L.
}

Николаев С. М., Чукаев С. А., Роднаева О. А., Хитрихеев В. Е.

\section{(C) Николаев Сергей Матвеевич}

доктор медицинских наук, профессор,

Бурятский государственный университет имени Доржи Банзарова

Россия, 670002, г. Улан-Удэ, ул. Октябрьская, 36а

Институт общей и экспериментальной биологии СО РАН

Россия, 670047, г. Улан-Удэ, ул. Сахьяновой, 6

smnikolaev@mail.ru

\section{(C) Чукаев Сергей Александрович}

кандидат медицинских наук, доцент, s.chukaev@mail.ru

\section{(C) Роднаева Ольга Анатольевна}

кандидат биологических наук, доцент, rodnaeva@mail.ru

\section{(C) Хитрихеев Владимир Евгеньевич}

доктор медицинских наук, профессор, chitricheev@mail.ru

Бурятский государственный университет имени Доржи Банзарова Россия, 670002, г. Улан-Удэ, ул. Октябрьская, 36а

\begin{abstract}
Аннотация. В данной статье представлены результаты исследований желчегонного действия экстракта сухого Carthamus tinctorius в условиях эксперимента.

Задачей исследований являлось определение желчегонного действия экстракта сухого из надземной части Carthamus tinctorius у интактных белых крыс.

Методы исследований. Экстракт получен путем экстракции растительного сырья 70\%-ным этанолом с использованием ультразвуковой обработки при соотношении cырье: экстрагент 1:15. В полученном экстракте содержится значительное количество биологически активных веществ фенольной природы. У интактных наркотизированных крыс массой 180-200 г желчь собирали через каждый час в течение 4 часов подряд. Экстракт в экспериментально-терапевтических дозах 50-200 мг/кг вводили в 12-перстную кишку крыс, а в контроле - дистиллированную воду в эквиобъемном количестве. Статистическую обработку данных проводили с использованием критерия «U» Манна-Уитни.

Результаты исследований. При введении крысам экстракта Carthamus tinctorius наблюдали ускорение холеретической реакции у животных с повышением объема выделенной желчи, что обусловлено активацией синтеза желчных кислот. Установленное желчегонное действие полученного экстракта вызвано влиянием биологически активных веществ, преимущественно фенольных соединений, содержащихся в
\end{abstract}


экстракте. Известно, что вещества фенольной природы стимулируют желчеобразовательную и желчевыделительную функции печени. Очевидно, благодаря этому ускоряется желчевыделение под влиянием данного экстракта.

Ключевые слова: лекарственные растения, Carthamus tinctorius, надземная часть, экстракт сухой, фенольные соединения, интактные крысы, экспериментальные дозы, холеретическая реакция, желчегонное действие

\section{Для цитирования}

Желчегонное действие экстракта сухого Carthamus Tinctorius L. / С. М. Николаев, С. А. Чукаев, О. А. Роднаева, В. Е. Хитрихеев // Вестник Бурятского государственного университета. Медицина и фармация. 2021. № 1. С. 3-8.

Введение. Важной задачей расширения перечня отечественных растительных лекарственных средств является исследование фармакологических свойств извлечений растительного сырья [1;2; 5]. Широкий спектр биологически активных веществ, наличествующий в растениях, определяет их фармакологическую активность и направление применения в клинической и профилактической медицине $[2 ; 5 ; 6 ; 8]$. В этом аспекте интерес вызывает Carthamus tinctorius L., который широко используется в народной и традиционной медицине при лечении и профилактике многих заболеваний.

Задачей нашего исследования явилось определение желчегонного действия экстракта сухого Carthamus tinctorius в условиях эксперимента.

\section{Материалы и методы исследований}

Экстракт сухой из надземной части Carthamus tinctorius получен доктором фармацевтических наук Д. Н. Олениковым и кандидатом фармацевтических наук Н. И. Кащенко путем экстрагирования растительного сырья 70\%-ным этанолом в соотношении сырье: экстрагент 1:15 с применением ультразвуковой обработки в течение 60 мин. В последующем проведены концентрирование и высушивание извлечения в вакуум-сушильном шкафу. Полученный экстракт содержит в значительных количествах вещества фенольной природы. Эксперименты проведены весной 2020 г. на интактных белых крысах-самцах исходной массой 180-200 г, полученных из ФГБУН «Научный центр биомедицинских технологий» ФМБА России. Крысы линии Wistar содержались в условиях сертифицированного вивария Института общей и экспериментальной биологии СО РАН со свободным доступом к воде и корму (полноценный комбикорм ПК-120 для содержания лабораторных животных, ГОСТ-Р50258-92, производитель ООО «Лабораторкорм»). При проведении исследований руководствовались требованиями действующих нормативных документов: «Руководство по проведению доклинических исследований лекарственных средств» (2012); Приказ МЗ РФ за № 199н «Об утверждении правил надлежащей лабораторной практики» от 01.04.2016 г.; «Правила проведения работ с использованием экспериментальных животных»; «Правила, принятые Европейской конвенцией по защите позвоночных животных, используемых для экспериментальных и иных научных целей (Страсбург, 1986).

У интактных наркотизированных крыс (натрия тиопентал, 40 мг/кг, внутрибрюшинно) желчь собирали через каждый час в течение 4 часов подряд. Экстракт вводили животным непосредственно в 12-перстную кишку в экспериментально-терапевтических дозах 50, 100 и 200 мг/кг в форме водного раствора. В контроле крысам вводили по аналогичной схеме дистиллированную воду в экви- 
С. М. Николаев, С. А. Чукаев, О. А. Роднаева, В. Е. Хитрихеев. Желчегонное действие экстракта сухого Carthamus Tinctorius $L$.

объемном количестве. О желчегонном влиянии экстракта судили по скорости секреции и общему количеству выделенной желчи, а также по содержанию в ней желчных кислот, холестерина и билирубина ${ }^{1}$. Различия между данными в опытных группах с введением экстракта и контрольной группы с введением крысам дистиллированной воды оценивали с применением непараметрического критерия «U» Манна-Уитни ${ }^{2}$. Дизайн исследований одобрен этическим комитетом Института общей и экспериментальной биологии СО РАН (протокол № 3 от 02.02.2018).

\section{Результаты и их обсуждение}

Введение животным полученного экстракта Carthamus tinctorius сопровождается ускорением холеретической реакции, особенно при дозах 100 и 200 мг/кг (табл. 1). Так, экстракт в дозе 100 мг/кг способствует ускорению холереза на $24,0-29,3 \%$, а в дозе 200 мг/кг - до 31,0\% с повышением общего количества выделенной желчи за 2-4 часа опыта до 1206 мг/100, что связано с мобилизацией синтеза холатов гепатоцитами (табл. 2). Наряду с желчегонным действием экстракта наблюдали повышение холестерина в сецернируемой желчи под влиянием данного экстракта.

Установленное желчегонное действие экстракта из надземной части Carthamus tinctorius обусловлено содержанием в нем комплекса биологически активных веществ $[2 ; 3 ; 7 ; 8]$. В частности, в полученном экстракте в значительных количествах содержатся лютеолин, неокартамин, производные кемпферола, а также халконы, которые наряду с другими наличествующими природными веществами обусловливают выраженное желчегонное действие экстракта [3; 7; 9].

\section{Таблииа 1}

Влияние экстракта сухого из надземной части Carthamus tinctorius на холеретическую реакцию у интактных крыс

\begin{tabular}{|c|c|c|c|c|c|}
\hline \multirow[t]{2}{*}{ № } & \multirow[t]{2}{*}{ Условия опыта } & \multicolumn{4}{|c|}{ Скорость секреции желчи в течение 4 часов опыта, мг/мин·100 г } \\
\hline & & $1 \mathrm{\varphi}$ & 2 ч & 34 & 4 ч \\
\hline 1 & $\begin{array}{ll}\text { Контрольная группа } \\
\text { c введением } \\
(\mathrm{n}=8)\end{array}$ & $6,2 \pm 0,3$ & $5,8 \pm 0,3$ & $5,2 \pm 0,3$ & $5,2 \pm 0,3$ \\
\hline 2 & $\begin{array}{l}\text { Опытные группы с } \\
\text { введением экстрак- } \\
\text { та: } 50 \text { мг/кг }\end{array}$ & $6,2 \pm 0,3$ & $6,1 \pm 0,2$ & $5,3 \pm 0,2$ & $5,3 \pm 0,2$ \\
\hline & $100 \mathrm{мг/кг}$ & $6,4 \pm 0,2$ & $7,5 \pm 0,1^{*}$ & $6,4 \pm 0,2^{*}$ & $6,2 \pm 0,2^{*}$ \\
\hline & $200 \mathrm{Mг} / \mathrm{Кг}$ & $6,6 \pm 0,3$ & $7,8 \pm 0,2 *$ & $6,3 \pm 0,3 *$ & $6,0 \pm 0,3$ \\
\hline
\end{tabular}

Примечание: * - означает здесь и далее, что разница между данными опыта и контроля значимы при $\mathrm{p} \leq 0,05 ; \mathrm{n}$ - количество животных в группе.

\footnotetext{
${ }^{1}$ Руководство по проведению доклинических испытаний лекарственных средств. Ч. 1. Москва, 2012. 944 с.

2 Там же.
} 
Известно, что для веществ фенольной природы характерны противовоспалительные, желчегонные, спазмолитические, антиоксидантные, мембраностабилизирующие, иммуномодулирующие, адаптогенные и другие фармакологические свойства $[3 ; 7 ; 8]$. Очевидно, что с содержанием веществ фенольной природы в указанном экстракте и проявлением желчегонной активности связана популярность данного растения в народной и традиционной медицине.

Таблица 2

Влияние экстракта из надземной части Carthamus tinctorius на содержание общего количества желчи, желчных кислот, холестерина и билирубина

\begin{tabular}{|c|c|c|c|c|c|}
\hline \multirow[t]{2}{*}{ № } & \multirow[t]{2}{*}{ Условия опыта } & $\begin{array}{c}\text { Общее коли- } \\
\text { чество желчи } \\
\text { за 2-4 часа }\end{array}$ & $\begin{array}{c}\text { Желчные } \\
\text { кислоты }\end{array}$ & Билирубин & Холестерин \\
\hline & & мг/100 г & \multicolumn{3}{|c|}{$\mathrm{M} \Gamma \%$} \\
\hline 1 & $\begin{array}{l}\text { Контрольная } \\
\text { группа с введени- } \\
\text { ем } \mathrm{H}_{2} \mathrm{O}(\mathrm{n}=8)\end{array}$ & $972 \pm 37,0$ & 832,0 & 16,0 & 85,1 \\
\hline 2 & $\begin{array}{l}\text { Опытные группы } \\
\text { с введением экс- } \\
\text { тракта в дозах: } \\
50 \text { мг/кг }\end{array}$ & $1002 \pm 38,6$ & 934,8 & 17,0 & 115,9 \\
\hline & 100 мг/кг & $1206 \pm 30,4^{*}$ & 877,8 & 15,0 & 97,2 \\
\hline & 200 мг/кГ & $1194 \pm 40,1 *$ & 866,4 & 17,0 & 84,3 \\
\hline
\end{tabular}

\section{Выводы:}

- экстракт из надземной части Carthamus tinctorius оказывает в экспериментально-терапевтических дозах желчегонное действие;

- ускорение холеретической реакции под влиянием указанного экстракта обусловлено наличествующими в нем преимущественно веществ фенольной природы.

\section{Литература}

1. Лубсандоржиева П. Б., Ферубко Е. В., Даргаева Т. Д. Методологический подход к созданию многокомпонентных лекарственных растительных средств для лечения заболеваний органов пищеварения // Традиционная медицина. 2018. № 3. С. 35-39. Текст: непосредственный.

2. Митрофанова И. Ю., Яницкая А. В., Бутенко Д. В. Методологические основы выбора растительных объектов в качестве источников фитопрепаратов // Фундаментальные исследования. 2012. № 20(2). С. 405-408. Текст: непосредственный.

3. Николаев С. М. Фитофармакотерапия и фитофармакопрофилактика заболеваний. Улан-Удэ. 2012. 286 с. Текст: непосредственный.

4. Салова Т. Ю., Громова Н. Ю. Теоретические аспекты получения биологически активных веществ из растительного и животного сырья // Успехи современного естествознания. 2016. № 3. С. 39-43. Текст: непосредственный.

5. Самбукова Т. В., Овчинников Б. В., Ганапольский В. П. Перспективы использования фитопрепаратов в современной фармакологии // Обзоры по клинической фармакологии и лекарственной терапии. 2017. № 2. С. 56-63. Текст: непосредственный.

6. Соколов С. Я. Фитотерапия и фитофармакология. Руководство для врачей. Москва, 2000. 976 с. Текст: непосредственный. 
7. Agrawal A. D. Pharmacological activites of flavonoids: a review // International J. Pharmaceutical Sciences and Nanotechnology. 2011. № 4. P. 1394-1398.

8. Kumar S., Pandly A. Chemistry and biological activities of flavonoids: an review // The scientific world journal. 2013. 16 p. URL: http://dx.doi.org /10.1155/ 2019/162750/accessed (дата обращения: 09.06.2019).

9. Hirschfield G. M., Heathote E. I., Geshwin M. E. Pathogenesis of cholestatic liver disease and therapeutic approaches // Gastroenterology. 2010. Vol. 139. P. 1481-1496.

Статья поступила в редакцию 09.01.2021; одобрена после рецензирования 25.01.2021; принята к публикации 09.04.2021.

\section{CHOLERETIC ACTION OF CARTHAMUS TINCTORIUS L. DRY EXTRACT}

Nikolaev S. M., Chukaev S. A., Rodnaeva O. A., Khitrikheev V. E.

Sergey M. Nikolaev

Dr. Sci. (Medicine), Prof.

Dorzhi Banzarov Buryat State University

36a Oktyabrskaya St., Ulan-Ude 670002, Russia

Institute of General and Experimental Biology SB RAS,

6 Sakhynovoy St., Ulan-Ude 670047, Russia

smnikolaev@mail.ru

\section{Sergey A. Chukaev}

Dr. Sci. (Medicine), A/Prof.

chukaev@mail.ru

Olga A. Rodnaeva

Cand. Sci. (Biol.), A/Prof.

rodnaeva@mail.ru

Vladimir E. Khitrikheev

Dr. Sci. (Medicine), Prof.

chitricheev@mail.ru

Dorzhi Banzarov Buryat State University

36a Oktyabrskaya St., Ulan-Ude 670002, Russia

Abstract. The article presents the results of the research on the choleretic action of the dry extract from Carthamus tinctorius L. obtained in experimental studies.

The study was aimed at estimation of the choleretic action of dry extract from the aerial part of Carthamus tinctorius in intact white rats.

Research Methods. The extract was obtained by extraction of the plant material with $70 \%$ ethanol applying ultrasound treatment at a material-extraction ratio of 1:15. The extract obtained contains a significant amount of biologically active substances of phenolic nature. We collected bile in intact anesthetized rats weighing 180-200 g every hour for 4 . The extract at experimental-therapeutic doses of 50-200 mg / kg was injected into the duodenum of rats; the control group received distilled water in an equivalent volume. We statistically processed the data using Mann-Whitney U test. 
Research Results. We observed the acceleration of choleretic reaction with the expansion of the excreted bile volume due to activation of bile acid synthesis in animals treated with Carthamus tinctorius extract. The established choleretic action of the obtained extract is associated with the influence of biologically active substances, mainly, phenolic compounds contained in the extract. It is known that phenolic substances stimulate the biligenic and choleretic functions of the liver. We consider that bile secretion is accelerated under the influence of this extract due to its phenolic compounds.

Keywords: medicinal plants, Carthamus tinctorius, aerial part, dry extract, phenol compounds, intact rats, experimental doses, choleretic reaction, choleretic action

\section{For citation}

Nikolaev S. M., Chukaev S. A., Rodnaeva O. A., Khitrikheev V. E. Choleretic Action of Carthamus Tinctorius L. Dry Extract. Bulletin of Buryat State University. Medicine and Pharmacy. 2021; 1: 3-8 (In Russ.).

The article was submitted 09.01.2021; approved after reviewing 25.01.2021; accepted for publication 09.04.2021. 